\title{
Testosterone and grasp-reflex differences in human neonates
}

\author{
Uner Tan and Meliha Tan \\ BlackSea Technical University, Trabzon, Turkey
}

\begin{abstract}
According to the Geschwind-Behan-Galaburda (GBG) hypothesis, prenatal testosterone $(\mathrm{T})$ causes a slowing in the development of the left brain with a consequent compensatory growth in the right brain, creating a reverse organisation of the cerebral lateralisation. That is, left- and right-handedness might be associated with high and low prenatal $\mathrm{T}$ levels, respectively. To test this hypothesis, the relations of $\mathrm{T}$ levels (umbilical cord blood) to grasp-reflex strengths were studied in human neonates. Handedness was assessed by measuring the grasp-reflex strengths from the right and left hands in 10 trials from each hand alternatively. There were two handedness groups: right-handers ( $\mathrm{R}-\mathrm{L}$ significantly greater than zero) and left-handers (significantly smaller than zero). Contrary to the GBG model, the mean free $T$ concentration was found to be significantly higher in right-handers than left-handers for males and females. There was no significant difference in the total $\mathrm{T}$ levels between right- and left-handers. Free $\mathrm{T}$ concentrations positively correlated with $\mathrm{R}-\mathrm{L}$ grasp-reflex strengths, i.e. righthandedness increased as $\mathrm{T}$ increased, and left-handedness increased as $\mathrm{T}$ decreased. Contrary to these positive correlations, $T$ negatively correlated with the grasp-reflex strengths from the right and left hands. These results partly supported the GBG hypothesis for this spinal-motor-asymmetry model. Total T did not significantly correlate with grasp-reflex strengths. The results suggest that prenatal $\mathrm{T}$ may at least play a role in prenatal determination of spinal motor lateralisation, with a possible consequent upward regulation of cerebral lateralisation.
\end{abstract}

Testosterone is the quintessence of the Geschwind-Behan-Galaburda (GBG) model of cerebral lateralisation (Geschwind \& Behan, 1982; Geschwind \& Galaburda, 1985). Briefly, the elevated levels of $\mathrm{T}$ in utero were hypothesised to slow down the growth of the left brain with a consequent compensatory growth of the right brain. This would, in turn, decrease the degree of naturally occurring dominance of the left brain and increase the dominance of the right brain. This

Address correspondence to Professor Dr Uner Tan, BlackSea Technical University (KTU), Medical Faculty, Department of Physiology, Trabzon, Turkey. Email: unertan@mailcity.com or unertan100@netscape.net 
would cause a weakening of right-handedness towards left-handedness. As stated by Bryden, McManus, and Bulman-Fleming (1994, p. 104), "it is obvious that here we are dealing with a major scientific phenomenon, of sudden onset and immediate influence." This hypothesis, however, did not find a general support from the laterality community, although it actually was succesful in stimulating a great deal of research (e.g., Halpern, 1994).

To test the GBG hypothesis, the cerebral lateralisation should be longitudinally analysed from birth to death, as the human brain is under the influence of $\mathrm{T}$ within the entire lifespan of men and women. In this context, Tan et al. (1992) have quantitatively studied grasp reflex, a primitive spinal reflex, in human neonates. They found that the mean grasp-reflex strength was significantly higher for the right than left hand, but only for the female neonates; the difference between hands was not significant in males. A tendency towards symmetry in males was found to be a result of a stronger grasp reflex from the left hand in males than females; the mean grasp-reflex strengths from the right hand were not significantly different in males and females. Tan et al. (1992) had hypothesised that the grasp-reflex asymmetries might foreshadow the development of human hand preference. This argument was recently supported by Hepper, McCartney, and Shannon (1998) as well as by McCartney and Hepper (1999), who observed the left and right arm movements of human foetuses at 10 to 27 weeks gestational age and found that there was a highly significant preference for them to move their right arms (83.3-85\%) rather than their left arms. These authors have suggested that asymmetric motor control is probably under muscular or spinal, rather than cortical, control. They have further suggested that the lateralised motor behaviour in early gestation may have a potential causative role for subsequent lateralised behaviour and asymmetric development of the human brain.

Generally, the reports of Tan and his co-workers concerning the Thypothesis for cerebral lateralisation seem to be rather inconsistent. In other words, their results depended on the methods they used-different methods yielded different results. For instance, Tan and Zor (1994) have reported that the neonatal graspreflex strengths from the right and left hands inversely correlated with serum $\mathrm{T}$ levels in neonates with right ear out in utero position; the left dominance decreased and right dominance increased in females with left ear out in utero position. In adults, Tan (1990) has reported that the right-and left-hand performances on a dot-filling task were inversely related to serum $\mathrm{T}$ levels in women; in men, the right-and left-hand performances were found to be directly and inversely related to $\mathrm{T}$, respectively. The $\mathrm{R}-\mathrm{L}$ hand performance did not exhibit a significant relation to T. Regarding hand preference, Tan (1991) has found that the mean serum $\mathrm{T}$ level was significantly greater in adults with anomalous dominance (left-handers, mixed-handers, and right-handers with familial sinistrality) than with standard dominance (consistent right-handers without familial sinistrality). In line with Bryden et al. (1994, p. 151), “... the 
apparent inconsistencies in the effects on preference and on skill, it is unclear how best to interpret these data." There are further inconsistent results with regard to the GBG model of cerebral lateralisation (see Bryden et al., 1994). Most recently, Elkadi, Nicholls, and Clode (1999) have also tested the GBG model in dizygotic twins with the expectation that males with a male twin will have been exposed to more $\mathrm{T}$, and hence should be more likely to be lefthanded, compared to males with an opposite-sex twin. There was no difference between the opposite and same-sex twins for either sex. These results did not support the GBG's T hypothesis. In adults, Moffat and Hampson (1996) have found that left-handers showed lower salivary $\mathrm{T}$ concentrations than righthanders, entirely opposite to the GBG hypothesis.

Grimshaw, Bryden, and Finegan (1993) have used a more direct approach to test the $\mathrm{T}$ hypothesis of handedness. These authors and Grimshaw, Bryden, and Finegan (1995) measured fetal $\mathrm{T}$ in amniotic fluid at 16 weeks of gestational age and followed the development of hand preference in children. Interestingly enough, the right-handers had higher $\mathrm{T}$ levels than the left-handers. This was consistent with Moffat and Hampson's findings (see earlier). In light of these reports entirely contrary to GBG's propositions, we have decided to study the grasp-reflex asymmetries in relation to serum $\mathrm{T}$ levels in human neonates, to test further the $\mathrm{T}$ hypothesis of human handedness.

\section{METHOD}

The present study was conducted at the Research Hospital of Ataturk University, Erzurum, Turkey. Following approval by the Ethical Committee, 116 full-term neonates (55 males and 61 females) were examined for the grasp reflex between the 3rd and 5th days after birth. The mothers were visited in the ward and asked for permission to test their babies. No mother denied our request.

The grasp-reflex strength was measured by a simple device (see Tan, 1994). A small balloon was attached to the piston-ring of an injector which was connected to an ohmmeter and ammeter. This balloon was brought into contact with the palmar surface of the neonate's hand. The fingers were reflexly closed (grasp reflex) and the resistance on the ohmmeter decreased, while the current increased as measured by the ammeter. Ten reflexes were alternately measured from the right and left hands in fully awake babies. As the grasp-reflex strengths correlated with weight, the ration of grasp-reflex strength to body weight was taken and multiplied by 1000 , to avoid very small values. The babies were considered as right-handed if the difference between the mean grasp-reflex strengths (corrected for weight) from the right and left hands $(\mathrm{R}-\mathrm{L})$ was greater than zero. The babies with $\mathrm{R}-\mathrm{L}<0$ were considered as left-handed. Grasp-reflex strengths were expressed as arbitrary units.

To measure the free and total $\mathrm{T}$ concentrations, blood samples were taken from the umbilical artery just after birth. The free and total $\mathrm{T}$ concentrations 
were then measured using a solid-phase, radioimmunoassay technique (Coat-ACount), which was commercially available (Diagnostic Products Corporation, USA). Neither serum $T$ levels nor grasp-reflex strengths were significantly related to gestational age (right hand: $t=0.40, \mathrm{df}=67, p>.05$; left hand: $t=$ $0.15, \mathrm{df}=67, p>.05 ; \mathrm{R}-\mathrm{L}: t=0.88, \mathrm{df}=67, p>.05$ ) and delivery time (right hand: $t=0.94$, df $=59, p>.05$; left hand: $t=0.36$, df $=59 . p>.05$; R-L: $t=$ $1.37, \mathrm{df}=59, p>.05)$.

\section{RESULTS}

\section{$\mathrm{R}-\mathrm{L}$ grasp-reflex strengths in males and females}

Table 1 presents the $\mathrm{R}-\mathrm{L}$ grasp-reflex strengths and the results of one sample $t$ test assessing the significance from zero for the right- and left-handed male and female neonates. The mean $\mathrm{R}-\mathrm{L}$ grasp reflex was found to be significantly greater in males than females, $t(114)=2.12, p<.05$.

\section{Testosterone concentrations in right- and left-handers}

Table 2 presents the mean $\mathrm{T}$ concentrations for the total sample, males, and females, also considering their handedness. In these three groups, the mean $\mathrm{T}$ concentration was found to be significantly higher in right-handers $(\mathrm{R}-\mathrm{L}>0)$ than left-handers $(\mathrm{R}-\mathrm{L}<0)$. The same ANOVA showed that there were no significant differences between the right- and left-handers for the mean total $\mathrm{T}$ levels of the total sample, $F(1,87)=2.60, p>.05$, males, $F(1,47)=0.81, p>$ .05 , and females, $F(2,37)=0.97, p>.05$. The mean free $\mathrm{T}$ concentration was found to be significantly greater in males than females for the total sample, $t(114)=3.07, p<.005$, and right-handers, $t(69)=2.06, p<.05$, but not for lefthanders, $t(43)=1.03, p>.05$.

TABLE 1

Grasp-reflex strengths and t-test results

\begin{tabular}{lcrrrrc}
\hline Subjects & $N$ & Mean & s.d. & $t$ & $d f$ & $p$ \\
\hline Males & 55 & 0.15 & 0.30 & 3.73 & 54 & $<.001$ \\
RHs & 39 & 0.32 & 0.14 & 14.55 & 38 & $<.001$ \\
LHs & 16 & -0.26 & 0.16 & -6.74 & 15 & $<.001$ \\
Females & 61 & 0.02 & 0.41 & 0.53 & 60 & NS \\
RHs & 32 & 0.37 & 0.16 & 12.97 & 31 & $<.001$ \\
LHs & 29 & -0.35 & 0.24 & -7.79 & 28 & $<.001$ \\
\hline
\end{tabular}

The mean R-L grasp-reflex strengths and the results of one-sample $t$-test (difference from zero) for the right- and left-handed male and female neonates. 
TABLE 2

Testosterone concentrations

\begin{tabular}{lrlllll}
\hline Subjects & $N$ & Mean & s.d. & $F$ & d.f. & $p$ \\
\hline Total & 116 & & & & & \\
$\quad$ Right-handers & 71 & 7.44 & 2.67 & & & \\
$\quad$ Left-handers & 45 & 4.10 & 2.41 & 46.64 & 1,114 & $<.001$ \\
Males & 55 & 7.08 & 3.12 & & & \\
$\quad$ Right-handers & 39 & 8.10 & 2.95 & & & \\
$\quad$ Left-handers & 16 & 4.59 & 1.93 & 19.05 & 1,53 & $<.001$ \\
Females & 61 & 5.35 & 2.94 & & & \\
$\quad$ Right-handers & 32 & 6.74 & 2.51 & & & \\
$\quad$ Left-handers & 29 & 3.82 & 2.63 & 19.58 & 1,58 & $<.001$ \\
\hline
\end{tabular}

Mean testosterone concentrations (ng/dL), standard deviations (s.d.) and results of ANOVA for the right- and left-handed neonates.

\section{Correlation analysis}

Table 3 presents the results of correlations between free $T$ concentrations and grasp-reflex strengths from the right hands, left hands, and R-L hands for the male and female neonates. For males, the grasp-reflex strength from the right hand was not significantly correlated with serum $T$, but the grasp-reflex from the left hand was found to be negatively linearly correlated with serum $T$ levels. The $\mathrm{R}-\mathrm{L}$ grasp reflex positively linearly correlated with $\mathrm{T}$ in these subjects. For females, $T$ negatively linearly correlated with grasp reflex from both right and left hands. As in the male neonates, there was a positive linear correlation between $\mathrm{T}$ and $\mathrm{R}-\mathrm{L}$ grasp reflex strength, i.e., right-handedness increased as $\mathrm{T}$

TABLE 3

Serum T-levels and grasp-reflex strength

\begin{tabular}{lccc}
\hline Subjects & $r$ & $t$ & $p$ \\
\hline Males & & & \\
$\quad$ Right hand & -0.19 & -1.39 & $\mathrm{NS}$ \\
$\quad$ Left hand & -0.80 & -9.94 & $<.001$ \\
R-L hand & +0.44 & +3.55 & $<.001$ \\
Females & & & \\
$\quad$ Right hand & -0.84 & -10.6 & $<.001$ \\
$\quad$ Left hand & -0.78 & -8.47 & $<.001$ \\
R-L hand & +0.43 & +3.22 & $<.005$ \\
\hline
\end{tabular}

Correlational analysis for the relations of serum $\mathrm{T}$ levels to the mean grasp-reflex strengths from the right hands, left hands, and $\mathrm{R}-\mathrm{L}$ hands for the male and female neonates. 
increased and left-handedness increased as $\mathrm{T}$ decreased. There were no significant correlations between serum total $\mathrm{T}$ and $\mathrm{R}-\mathrm{L}$ grasp-reflex strengths for the total sample, males, and females. Figure 1 illustrates the linear correlations between serum free-T levels vs grasp-reflex strengths for the right hand (A), left hand (B), and R-L difference in females (closed circles) and males (open circles). As the male and female data were close to each other, all the data were represented by a single regression line. In doing so, there were significant negative linear correlations between the free $\mathrm{T}$ levels and the graspreflex strengths from the right and left hands, right hand: $r(114)=-.30, t=$ $-3.16, p<.005$; left hand: $r(114)=-.67, t=-7.92, p<.001$. Contrary to these negative correlations, there was a significant positive linear correlation between the free $\mathrm{T}$ levels and $\mathrm{R}-\mathrm{L}$ grasp-reflex strengths, $r(114)=+.58, t=$ $+6.99, p<.001$.

\section{DISCUSSION}

The females had a symmetric distribution of the mean $\mathrm{R}-\mathrm{L}$ grasp-reflex strength, R-L not being significantly different from zero, contrary to males exhibiting a significantly right-shifted grasp reflex. These results are not consistent with those previously reported by Tan et al. (1992), showing a more symmetric grasp reflex in males than females, but consistent with the generally accepted notion that males tend to exhibit more accentuated asymmetries compared to females who exhibit more diffuse lateralisation patterns (for a review see Wisniewski, 1998).

Following the GBG model of cerebral lateralisation, it was hypothesised that right-handed neonates would have lowest $\mathrm{T}$ concentrations, and vice versa for left-handers. To test this hypothesis, the free and total $\mathrm{T}$ levels were measured in the umbilical cord blood of human neonates in the present work. It was expected that free $\mathrm{T}$ would be more effective in grasp reflex vs $\mathrm{T}$ relations, as plasma-free $\mathrm{T}$ (i.e., $\mathrm{T}$ not bound to SHBG) is a more direct measure of circulating biologically active $\mathrm{T}$ than total $\mathrm{T}$ (see Greenspan, 1991, p. 339). In line with this prediction, only free $\mathrm{T}$ was found to show significant results. In doing so, it was found that right-handers had the highest $\mathrm{T}$ levels and left-handers had the lowest $\mathrm{T}$ concentrations in males and females. These results are apparently inconsistent with the GBG hypothesis, but consistent with the findings of Grimshaw et al. (1993, 1995), who measured foetal $\mathrm{T}$ in amniotic fluid and found strong association of right-handedness with high T levels. Similarly, Moffat and Hampson (1996) have reported that right-handed adults had higher $\mathrm{T}$ concentrations than left-handed adults. Taken together, these results suggested that $\mathrm{T}$ may, at least in part, play a role in the development of human handedness, but in the opposite direction from what the GBG model suggests, provided that spinal motor lateralisation is a good predictor for human handedness. Accordingly, Tan and Tan (1999) have recently reported that $8.3 \%$ of human 

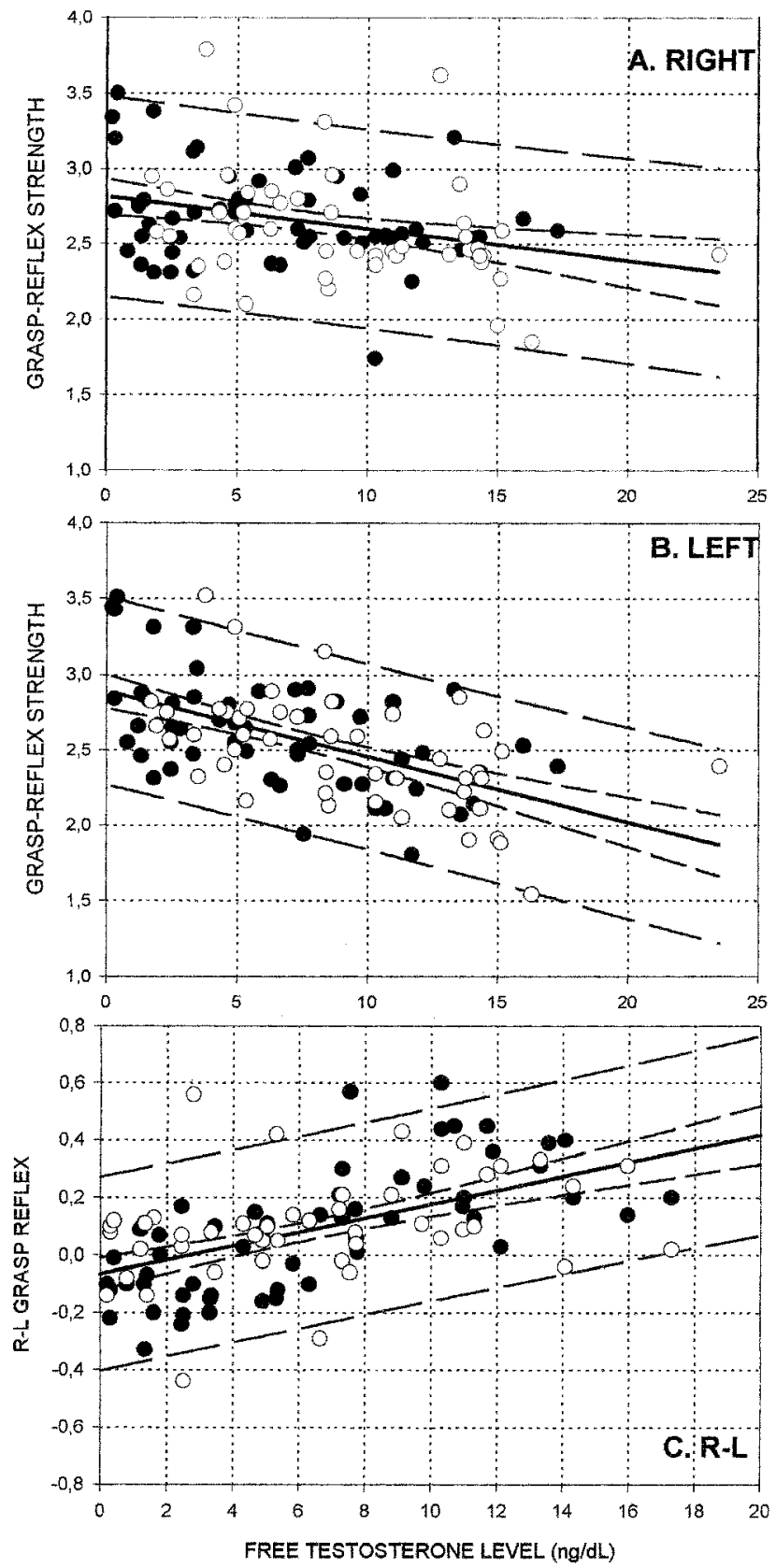

Figure 1. Linear correlations between serum free-testosterone levels and grasp-reflex strengths for the right hand (A), left hand (B), and R-L hand (C) for the male (open circles) and female (closed circles) neonates. 
neonates exhibited left-handedness in R-L grasp-reflex strength, which is very close to the incidence of left-handedness in human adults. This suggests that left-handedness may be largely determined before birth under low testosterone milieu in addition to a probable genetic control, and the spinal motor lateralisation may be taken as an index to predict handedness in adults.

In line with the greater right-handedness of males ( $\mathrm{R}-\mathrm{L}$ significantly greater than zero) than females (R-L not significantly different from zero), serum $\mathrm{T}$ level was found to be significantly higher in males than females. This also supports the results showing that right-handers have higher $\mathrm{T}$ levels than lefthanders. Similarly, it has been reported that male gerbils have higher circulating T concentrations than do females (Clark, Crews, \& Galef, 1991; Clark, vom Saal, \& Galef, 1992). Moreover, testosterone levels in amniotic fluid (between 14 and 20 gestational weeks) was also found to be significantly higher for boys than for girls (Dörner, 1976; Finegan, Bartleman, \& Wong, 1989; Grimshaw et al., 1995). Because of these similar sex differences in T levels for the umbilical cord blood and amniotic fluid, the $\mathrm{T}$ concentration in the umbilical cord blood may reflect that in the foetal circulation. Testosterone in foetal blood may affect the spinal neurons, as there is evidence that spinal neurons possess sex steroid receptors (Keefer, Stumpf, \& Sar, 1973; Sar \& Stumpf, 1977) and motoneurons have messenger RNAs for the androgen receptor (Simerly, Chang, Muramatsu, \& Swanson, 1990). So, the spinalmotor system may be taken as a model to study the $\mathrm{T}$ vs neural relations.

To understand $\mathrm{T}$ mechanisms for the emergence of handedness, we used correlational analysis, because of ethical considerations. Accordingly, $\mathrm{T}$ in males was inversely correlated with grasp-reflex strength, but only from the left hand, not from the right hand. In females, $T$ was inversely correlated with the grasp-reflex strengths from both hands. Thus, the $\mathrm{R}-\mathrm{L}$ difference in grasp reflex originated from a worse left side in males, the right side remaining constant. This is actually in line with the GBG model which proposes that $\mathrm{T}$ may retard the normal development of the left brain only, but the prediction of this model was far from perfect, i.e., the GBG could not realise the fact that T to "R-L", would be positive, towards right-handedness, despite its negative relations to right and/or left sides separately. The GBG model of cerebral lateralisation also did not consider possible sex differences, probably because they did not have any support suggesting this possibility, namely, for males, a negative correlation between $\mathrm{T}$ and left side (only) promotes right-handedness in males, but a negative correlation between $\mathrm{T}$ and grasp-reflex strength from the right and left sides may promote right-handedness in females.

Testosterone may retard the development of the right and left brains in females, but at different rates. This may also cause a right-left difference towards right-handedness as mentioned earlier. Such a maturational gradient, a differential rate of growth of the right and left brains, was suggested much earlier by Morgan (1977) and Corballis and Morgan (1978). Our results now 
suggest that a maturational gradient may originate from in utero $\mathrm{T}$ affecting both sides differentially. The original GBG hypothesis was later modified by Rosen, Sherman, and Galaburda (1991) who reported that asymmetry does not result from retarded growth of the left hemisphere, but rather from enhanced growth of the right hemisphere. Our results showing inverse correlations between $\mathrm{T}$ and grasp-relex strengths from the right and left hands are inconsistent with this argument, provided that spinal cord might be considered as a suitable model for $\mathrm{T}$ actions for cerebral lateralisation.

The results of the present work suggest that $\mathrm{T}$ may decrease the number of motoneurons or interneurons contributing to the polysynaptic grasp reflex, but different degrees of this action may cause the whole spectrum of spinal motor lateralization (Tan, 1984, 1985). As the cerebral cortex is not yet developed during perinatal period, it is possible that cortical motor lateralisation develops later under the feedback control of the spinal motor system. It is well known that the brain has highly plastic properties. i.e., it can change its structure and function under environmental inputs such as sensory stimulation, gonadal hormones, trophic factors, and experience (see Filipkowski et al., 2000; Kolb \& Whishaw, 1998; Sanes \& Donoghue, 2000). There are also reports indicating an early parcellation of the cerebral cortex during foetal development (Levitt, Barbe, \& Eagleson, 1997). Current models of cortical plasticity emphasise the importance of the conjoint activity of somatosensory afferents. Stefan et al. (2000) have tested spinal motoneuronal excitability and electrically stimulated the brain stem, and established topographically specific enhancement of synaptic efficacy in the human motor cortex. They have proposed that "the induced plasticity may represent a signature of associative long-term potentiation of cortical synapses or closely related neuronal mechanisms in the human cortex" (2000, p. 1) This synaptic plasticity, in turn, may underly cortical map reorganisation (see Buonomano \& Merzenich, 1998).

Androgens and their metabolites organise the brain during critical periods early in life (organisational influences of sex hormones); fluctuations in hormone levels in adulthood may alter these original patterns (activational influences) (see Kimura, 1996). Accordingly, the neonatal T measured in the present work may be involved in the organisational effects that we were looking for. Clark, Santamaria, Robertson, and Galef (1998) have provided strong evidence of organisational effects and weaker evidence of activational effects of gonadal hormones on lateral asymmetries in forelimb use by Mongolian gerbils.

The $\mathrm{T}$ levels measured just after birth may, of course, not reflect a steady $\mathrm{T}$ level during the prenatal period, as $\mathrm{T}$ levels are known to fluctuate during prenatal development. However, we measured $\mathrm{T}$ levels at the end of prenatal development and tried to correlate them with grasp-reflex excitability, also at the end of the prenatal development. So, there is no time lag between these measures, to cause us to draw wrong conclusions. Moreover, we do not think that small fluctuations in hormonal levels during the prenatal period would 
significantly disturb the relations of $\mathrm{T}$ to grasp-reflex asymmetries for our large sample size. Another concern about this work might be the differential rates of cerebral development in males and females. However, there is no report regarding the differential rates of spinal development in males and females. In fact, the grasp reflex may be well developed at birth, as it emerges at around 11 weeks in utero and is suppressed at about 2-4 months after birth (Lorenz, 1937; Polack, 1960; Stirnimann, 1941).

\section{CONCLUSION}

In the present work, the GBG model of cerebral lateralisation was tested by measuring the grasp reflex from the right and left hands in relation to serum $T$ levels in human neonates. Contrary to the GBG's hypothesis, the right-handers had the highest and left-handers had the lowest $\mathrm{T}$ concentrations. The R-L grasp reflex positively correlated with $\mathrm{T}$, indicating an increase in the degree of righthandedness as $\mathrm{T}$ increased and an increase in the degree of left-handedness as $\mathrm{T}$ decreased. To understand the mechanisms of these relations, the grasp-reflex strengths from the right and left hands were correlated separately with serum $\mathrm{T}$ levels. Interestingly enough, T inversely correlated with grasp-reflex strength for the left hand only in males and for both hands in females. These results supported the GBG hypothesis in essence and showed how two negative correlations can yield positive correlations after considering their differences. Our results suggested that $\mathrm{T}$ acting on the right and left sides differentially and slowing the development of both sides in different degrees, may create an asymmetric spinal motor system, which, in turn, may stimulate the development of a cortical motor laterality.

Manuscript received 5 August 1999 Revised manuscript received 10 July 2000

\section{REFERENCES}

Bryden, M.P., McManus, I.C., \& Bulman-Fleming, M.B. (1994). Evaluating the empirical support for the Geschwind-Behan-Galaburda model of cerebral lateralization. Brain and Cognition, 26, 103-167.

Buonomano, D.V., \& Merzenich, M.M. (1998). Cortical plasticity: From synapses to maps. Annual Reviews of Neuroscience, 21, 149-186.

Clark, M.M., Crews, D.,\& Galef, B.G. (1991). Concentrations of sex steroid hormones in pregnant and fetal Mongolian gerbils. Physiology and Behavior, 49, 239-243.

Clark, M.M., Santamaria, B.T., Robertson, R.K., \& Galef, B.G. (1998). Effects of gonadectomy in infancy and adulthood on handedness in male and female Mongolian gerbils. Behavioral Neurosience, 112, 1026-1029.

Clark, M.M., Von Saal, F.S., \& Galef, B.G. (1992). Intrauterine positions and testosterone levels of adult male gerbils are correlated. Physiology and Behavior, 51, 957-960. 
Corballis, M.C., \& Morgan, M.J. (1978). On the biological basis of human laterality: I. Evidence for a maturational left-right gradient. The Behavioral and Brain Sciences, 1, 261-269.

Dörner, G. (1976). Hormones and brain differentiation. Amsterdam: Elsevier.

Elkadi, S., Nicholls, M.E.R., \& Clode, D. (1999). Handedness in opposite and the same-sex dizygotic twins: Testing the testosterone hypothesis. NeuroReport 10, 333-336.

Filipkowski, R.K., Rydz, M., Berdel, B., Morys, J., \& Kaczmarek, L. (2000). Tactile experience induces c-fos expression in rat barrell cortex. Learning and Memory, 7, 116-122.

Finegan, J.J., Bartleman, B., \& Wong, P.Y. (1989). A window for the study of prenatal sex hormone influences on postnatal development. Journal of Genetic Psychology, 150, 191-112.

Geschwind, N., \& Behan, P. (1982). Left-handedness: Association with immune disease, migraine, and developmental learning disorder. Proceedings of the National Academy of Sciences USA, 79, 5097-5100.

Geschwind, N., \& Galaburda, A.M. (1985). Cerebral lateralization, biological mechanisms, associations, and pathology: I. A hypothesis and a program for research. Archives of Neurology, 42, 428-459.

Greenspan, F.S. (1991). Basic and clinical endocrinology. London: Appleton \& Lange.

Grimshaw, G.M., Bryden, M.P., \& Finegan, J.K. (1993). Relations between prenatal testosterone and cerebral lateralization at age 10. Journal of Clinical and Experimental Neuropsychology, $15,39-40$.

Grimshaw, G.M., Bryden, M.P., \& Finegan, J.K. (1995). Relations between prenatal testosterone and cerebral lateralization in children. Neuropsychology, 9, 68-79.

Halpern, D.F. (1994). Evaluating support for the Geschwind-Behan-Galaburda Model: With a rubber ruler and a thumb on the scale. Brain and Cognition, 26, 185-190.

Hepper, P.G., McCartney, G.R., \& Shannon, E.A. (1998). Lateralized behaviour in first trimester human foetuses. Neuropsychologia, 36, 531-534.

Keefer, D.A., Stumpf, W.E., \& Sar, M. (1973). Topographical localization of estrogen-concentrating cells in the rat spinal cord following H-stradiol administration. Proceedings of the Society for Experimental Biology and Medicine, 143, 414-417.

Kimura, D. (1996). Sex, sexual orientation and sex hormones influence human cognitive function. Current Opinion in Neurobiology, 6, 259-263.

Kolb, B., \& Whishaw, I.Q. (1998). Brain plasticity and behavior. Annual Review of Psychology, 49, 43-64.

Levitt, P., Barbe, M.F., Eagleson, K.L. (1997). Patterning and specification of the cerebral cortex. Annual Review of Neuroscience, 20, 1-24.

Lorenz, K. (1937). Die Bildung des Instinktbegriffes. Naturwissenschaften, 25, 289-300.

McCartney, G., \& Hepper, P. (1999). Development of lateralized behaviour in the human fetus from 12 to 27 weeks' gestation. Developmental Medicine of Child Neurology, 41, 83-86.

Moffat, S.D., \& Hampson, E. (1996). Salivary testosterone levels in left- and right-handed adults. Neuropsychologia, 34, 225-233.

Morgan, M.J. (1977). Embryology and inheritance of asymmetry. In S. Harnad, R.W. Doty, L. Goldstein, J. Jaynes, \& G. Krauthamer (Eds.), Lateralization in the nervous system. New York: Academic Press.

Polack, S. (1960). The grasp response of the neonate: Its characteristics and interaction with tonic neck reflex. Archives of Neurology, 3, 574-581.

Rosen, G.D., Sherman, G.F., \& Galaburda, A.M. (1991). Ontogenesis of neocortical asymmetry: A [3H] thymidine study. Neuroscience, 41, 779-790.

Sar, M., \& Stumpf, W.E. (1977). Androgen concentration in motor neurons of cranial nerves and spinal cord. Science, 197, 77-79.

Sanes, J.N., \& Donoghue, J.P. (2000). Plasticity and primary motor cortex. Annual Reviews of Neuroscience, 23, 393-415.

Simerly, R.B., Chang, C., Muramatsu, M., \& Swanson, L.W. (1990). Distribution of androgen and 
estrogen receptor mRNA-containing cells in the rat brain: An in situ hybridization study. Journal of Comparative Neurology, 294, 76-95.

Stefan, K., Kunesch, E., Cohen, L.G., Benecke, R., \& Classen, J. (2000). Induction of plasticity in the human motor cortex by paired associative stimulation. Brain, 123, 572-584.

Stirnimann, F. (1941). Greifversuche mit der Hand Neugeborener. Annual Paediatrie, 157, 17-27.

Tan, U. (1984). Lateral asymmetry of H-reflex recovery curves in cat: Evidence for a spinal motor asymmetry. International Journal of Neuroscience, 24, 45-52.

Tan, U. (1985). Left-right differences in the Hoffmann reflex recovery curve associated with handedness in normal subjects. International Journal of Psychophysiology, 3, 75-78.

Tan, U. (1990). Relation of testosterone and hand preference in right-handed young adults to sex and familial sinistrality. International Journal of Neuroscience, 53, 157-165.

Tan, U. (1991). Serum testosterone levels in male and female subjects with standard and anomalous dominance. International Journal of Neuroscience, 58, 211-214.

Tan, U. (1994). The grasp reflex from the right and left hand of human neonates indicates that the development of both cerebral hemispheres in males, but only the right hemisphere in females, is favoured by testosterone. International Journal of Psychophysiology, 16, 39-47.

Tan, U., Ors, R., Kurkcuoglu, M., Kutlu, N., \& Cankaya, A. (1992). Lateralization of the grasp reflex in male and female newborns. International Journal of Neuroscience, 62, 155-163.

Tan, U., \& Tan, M. (1999). Incidences of asymmetries for the palmar grasp reflex in neonates and hand preference in adults. NeuroReport, 10, 3253-3256.

Tan, U., \& Zor, N. (1994). Relation of free-testosterone level to grasp-reflex strength in human neonates with right-ear and left-ear facing out in-utero position. International Journal of Neuroscience, 75, 9-18.

Wisniewski, A.B. (1998). Sexually-dimorphic patterns of cortical asymmetries, and the role for sex steroid hormones in determining cortical patterns of lateralization. Psychoneuroendocrinology, $23,519-547$. 